\title{
Hubungan antara shift kerja, kelelahan kerja dengan stres kerja pada perawat
}

\author{
Indah Rhamdani ${ }^{1}$, Magdalena Wartono ${ }^{2}$
}

\begin{abstract}
ABSTRAK
\section{LATAR BELAKANG}

Stres kerja merupakan stres yang timbul akibat tuntutan kerja yang melebihi kemampuan seseorang untuk mengatasinya sehingga menimbulkan berbagai macam reaksi fisiologis, psikologis, dan perilaku. Menurut PPNI (Persatuan Perawat Nasional Indonesia), pada tahun 2007 sebanyak $50.9 \%$ perawat di Indonesia mengalami stres kerja. Beberapa faktor penyebabnya adalah kelelahan dan waktu kerja yang berubah-ubah (shift kerja). Hasil penelitian terdahulu memperlihatkan bahwa hubungan antara shift kerja maupun kelelahan kerja dengan stres kerja pada perawat masih diperdebatkan. Tujuan dari penelitian ini adalah untuk mengetahui hubungan antara shift kerja maupun kelelahan kerja dengan stres kerja pada perawat.
\end{abstract}

\section{METODE}

Studi ini merupakan penelitian observasional analitik dengan desain cross sectional pada 102 perawat di RSUD Asy-Syifa Sumbawa Barat. Cara pengambilan sampel berupa consecutive non random sampling. Data primer diperoleh dengan kuesioner data diri Kuesioner Alat Ukur Perasaan Kelelahan Kerja (KAUPK2) dan kuesioner stres kerja yang sudah divalidasi dengan nilai Alpha Cronbach antara 0.837-0.832 dan realibilitas 0.926. Analisis data menggunakan chi-square test dengan tingkat kemaknaan $(\mathrm{p})<0.05$.

\section{HASIL}

Terdapat hubungan antara shift $\operatorname{kerja}(\mathrm{p}=0.035)$, kelelahan kerja $(\mathrm{p}=0.022)$, jenis kelamin (0.037) dan status pernikahan $(\mathrm{p}=0.041)$ dengan stres kerja dan tidak ada hubungan antara usia dengan stres kerja $(\mathrm{p}=0.071)$.

\section{KESIMPULAN}

Terdapat hubungan antara shift kerja, kelelahan kerja, jenis kelamin, dan status pernikahan dengan stres kerja pada perawat RSUD Asy-Syifa Sumbawa Barat. Akan tetapi usia tidak berkaitan dengan stres kerja.
${ }^{1}$ Program Studi Kedokteran, Fakultas Kedokteran Universitas Trisakti, Indonesia

2 Departemen Anatomi, Fakultas Kedokteran Universitas Trisakti, Indonesia

\section{Korespondensi:}

Magdalena Wartono

Departemen Anatomi, Fakultas

Kedokteran Universitas Trisakti,

Indonesia, Jalan Kyai Tapa No. 260, Grogol, Jakarta Barat

Email: magdalena_w@trisakti.ac.id

J Biomedika Kesehat 2019;2(3):104-

110

DOI: 10.18051/JBiomedKes.2019.

v2.104-110

pISSN: 2621-539X / eISSN: 2621-5470

Artikel akses terbuka (open access) ini didistribusikan di bawah lisensi Creative Commons Attribution 4.0 International (CC-BY 4.0)

Kata kunci : perawat, stres kerja, shift kerja, kelelahan kerja 


\section{ABSTRACT}

\section{Relationship of shift work and fatigue with job stress in nurses}

\section{BACKGROUND}

Job stress is a stress that caused by incapability of someone to overcome the exceeding job demands and cause various kinds of physiological, psychological, and behavioral reactions. According to the PPNI (Persatuan Perawat Nasional Indonesia) survey in 2007, 50.9\% of Indonesian nurses experienced job stress. Some of the risk factors are fatigue and shift work. Studies result previously showed that relationship of shift work and work fatigue with job stress in Nurses are debatable. This study was conducted to determine the relationship between work shift, work fatigue and job stress in nurses.

\section{METHODS}

This study was an analytic observational with cross-sectional design towards 102 nurses in RSUD Asy-Syifa Sumbawa Barat. The subjects were chosen with consecutive non-random sampling. Data was collected by using questionnaires for self-indentification, measure perceptions of fatigue felt by nurses with Kuesioner Alat Ukur Perasaan Kelelahan Kerja (KAUPK2) and Job Stress questionnaires were validated with Alpha Cronbach between 0.837-0.832 and 0.926 for realibility. Statistical analysis were done by Chi-Square test with a significance level $<0.05$.

\section{RESULT}

There was a relationship between shift work $(\mathrm{p}=0.035)$, work fatigue $(\mathrm{p}=0.022)$, gender $(\mathrm{p}=0.037)$ and marital status $(\mathrm{p}=0.041)$ with job stress and no relationship between age and job stress $(\mathrm{p}=0.071)$.

\section{CONCLUSION}

There was a significant relationship between shift work, work fatigue, gender, and marital status with job stress in nurses; and the results of this study also shows no relationship between age and job stress.

Keywords : nurse, work stress, work shift, work fatigue

\section{PENDAHULUAN}

Berdasarkan Peraturan Menteri Kesehatan Republik Indonesia No.659/MENKES/PER/ VIII/2009 tentang Rumah Sakit Indonesia kelas Dunia, rumah sakit adalah fasilitas pelayanan kesehatan yang menyelenggarakan pelayanan kesehatan perorangan secara paripurna yang menyediakan pelayanan rawat inap, rawat jalan, dan gawat darurat. ${ }^{(1)}$ Perawat merupakan salah satu tenaga medis yang memberikan pelayanan untuk menunjang kesembuhan pasien. Pelayanan yang diberikan berdasarkan pendekatan bio-psikososial-spiritual yang dilakukan selama 24 jam dan berkesinambungan. Tuntutan dan kebutuhan serta pelayanan kesehatan yang kontinu dan sistematis inilah yang sering menimbulkan kondisi yang dapat memicu terjadinya stres kerja pada perawat. (2)

\section{American National Institutes of Health} (NIH) mengatakan bahwa di antara 130 jenis pekerjaan yang penuh dengan stres, perawat berada di peringkat ke-27. ${ }^{(3)}$ Stres adalah gangguan pada tubuh dan pikiran yang disebabkan oleh perubahan dan tuntutan kehidupan, yang dipengaruhi baik oleh lingkungan maupun penampilan individu di lingkungan tersebut. ${ }^{(4)}$ Stres juga merupakan keadaan tegang secara biopsikososial akibat dari banyak tugas-tugas perkembangan yang dihadapi seseorang dalam kesehariannya, baik dalam kelompok sebaya, keluarga, sekolah, maupun pekerjaan. ${ }^{(5)}$

Stres kerja adalah stres yang timbul dari tuntutan kerja yang melebihi kemampuan seseorang untuk mengatasinya sehingga dapat menimbulkan berbagai macam reaksi, berupa reaksi fisiologis, psikologis dan perilaku. ${ }^{(5)}$ Penelitian di Iran memperlihatkan $75 \%$ perawat mengalami stres sedang dan tinggi. ${ }^{(6)}$ Hasil survei dari Persatuan Perawat Nasional Indonesia (PPNI) pada tahun 2007 didapatkan sebanyak 50.9\% perawat Indonesia yang bekerja mengalami stres kerja. ${ }^{(7)}$

Stres kerja pada perawat sangat merugikan bagi dirinya maupun organisasinya karena bisa membuat perawat menderita kelehahan, bersikap kasar, cemas, tekanan darah meningkat, berkurangnya percaya diri, meningkatnya ketidakpuasan terhadap pekerjaan dan menurunkan produktifitas kerja. ${ }^{(8)}$ Stres kerja pada perawat dapat memberikan dampak yang signifikans pada kualitas hidup mereka dan juga performa mereka di semua aspek termasuk di dalamnya pelayanan kepada pasien dan keselamatan pasien. ${ }^{(9,10)}$

Menurut National Safety Council


penyebab stres kerja dapat dikategorikan menjadi tiga karakteristik yaitu karakteristik organisasional, individual dan lingkungan. Karakteristik organisasional meliputi kurangnya otonomi, mutasi, karier, beban kerja, interaksi, masa kerja dan juga shift kerja terutama shift malam yang dapat menyebabkan terjadinya kelelahan. Karakteristik individual yang meliputi dukungan keluarga, kejenuhan, konflik dengan rekan kerja, usia, jenis kelamin dan status pernikahan. Karakteristik lingkungan meliputi kebisingan dan polusi. ${ }^{(7,11,12)}$ Penelitian terdahulu menunjukkan hubungan antara usia dengan stres kerja $(\mathrm{p}=0.031)$. (13) Tetapi penelitian lain memperlihatkan hasil yang berbeda, yaitu tidak ada hubungan antara usia, jenis kelamin dan status pernikahan dengan stres kerja. ${ }^{(14)}$

Shift kerja merupakan pilihan dalam pengorganisasian kerja untuk memaksimalkan produktivitas kerja sebagai pemenuhan tuntutan pasien. ${ }^{(15)}$ Hasil penelitian terdahulu memperlihatkan $45.2 \%$ perawat shift malam mengalami stres kerja, ${ }^{(16)}$ tetapi penelitian lain memperlihatkan tidak ada hubungan antara shift kerja dengan stress pada perawat. ${ }^{(17)}$

Kelelahan kerja yang tidak dapat diatasi dapat menimbulkan berbagai permasalahan kerja yang fatal dan mengakibatkan kecelakaan kerja. ${ }^{(18)}$ Hasil penelitian terdahulu menunjukkan bahwa faktor kelelahan mempunyai hubungan yang signifikan dan tertinggi terhadap terjadinya stres kerja. ${ }^{(19,20)}$ Hasil penelitian lain memperlihatkan bahwa perawat yang bekerja di ICU, kelelahan kerja bukan merupakan faktor penyebab terjadinya stres kerja. ${ }^{(21)}$

Oleh karena masih terdapat perbedaan hasil penelitian sebelumnya maka peneliti memutuskan untuk melakukan penelitian guna menentukan hubungan antar shift kerja, kelelahan kerja, dan stres kerja pada perawat.

\section{METODE}

Penelitian ini merupakan jenis penelitian analitik observasional dengan menggunakan desain penelitian cross sectional, dan teknik pengambilan sampel secara consecutive non-random sampling. Sampel penelitian adalah 102 perawat yang memenuhi kriteria inklusi yaitu merupakan perawat yang masih bekerja di RSUD Asy-Syifa Sumbawa Barat dan bersedia menandatangani inform consent serta tidak memiliki kriteria eksklusi antara lain mempunyai riwayat penyakit kronik seperti diabetes mellitus, stroke, penyakit jantung koroner, dan keganasan. Data primer didapatkan dengan wawancara menggunakan kuesioner stres kerja yang sudah divalidasi dengan nilai Alpha Cronbach antara 0.837-0.832 dan dengan keseluruhan reabilitas 0.926 . $^{(5)}$ Serta kuesioner baku KAUPK2 (Kuesioner Alat Ukur Perasaan Kelelahan Kerja) yang sudah divalidasi. (22) Analisis data menggunakan uji Chi-square dan uji Fisher dengan tingkat kemaknaan sebesar 0.05.

\section{HASIL}

Tabel 1. Distribusi frekuensi karakteristik demografi, shift kerja, kelelahan kerja, dan stress kerja pada perawat di RSUD Asy-Syifa Sumbawa Barat

\begin{tabular}{lcc}
\hline Karakteristik & $\begin{array}{c}\text { Frekuensi } \\
(\mathbf{n}=\mathbf{1 0 2})\end{array}$ & $\begin{array}{c}\text { Persentase } \\
(\mathbf{\%})\end{array}$ \\
\hline Usia & & \\
$\quad$ <40 Tahun & 90 & 88.2 \\
$\quad>40$ Tahun & 12 & 11.8 \\
$\begin{array}{l}\text { Jenis kelamin } \\
\quad \text { Perempuan }\end{array}$ & 68 & 66.7 \\
$\quad$ Laki-laki & 34 & 33.3 \\
Status pernikahan & & \\
$\quad$ Menikah & 53 & 52.0 \\
$\quad$ Belum menikah & 49 & 48.0 \\
Masa kerja & & \\
$\quad>10$ Tahun & 7 & 6.9 \\
$\quad$ 5-10 Tahun & 53 & 52.0 \\
$\quad$ 5 Tahun & 42 & 41.2 \\
Shift kerja & & \\
$\quad$ Ya & 61 & 59.8 \\
$\quad$ Tidak & 41 & 40.2 \\
Kelelahan kerja & & \\
$\quad$ Kurang lelah & 27 & 26.5 \\
$\quad$ Lelah & 46 & 45.1 \\
$\quad$ Sangat lelah & 29 & 28.4 \\
Stres kerja & & \\
$\quad$ Ya & 76 & 74.5 \\
$\quad$ Tidak & 26 & 25.5 \\
\hline
\end{tabular}

Keterangan: $n=$ jumlah subjek (sampel)

Jumlah total perawat di RSUD AsySyifa Sumbawa Barat adalah 115 orang. Tiga belas perawat yang tidak memenuhi kriteria inklusi dan memenuhi kriteria eksklusi sehingga total responden adalah 102 perawat. Penelitian dilakukan pada bulan Februari-Maret 2018 dan diperoleh hasil pada Tabel 1 dan Tabel 2.

Berdasarkan Tabel 1 dapat dilihat bahwa dari 102 responden, frekuensi terbanyak adalah responden yang berusia $\leq 40$ tahun yaitu berjumlah 90 orang $(88.2 \%)$ dan didominasi oleh perempuan 
yaitu sebanyak 68 orang (66.7\%). Di RSUD Asy-Syifa Sumbawa Barat kebanyakan perawat merupakan pekerja shift yaitu 61 orang $(59.8 \%)$, rata-rata sudah menikah (52\%) dan banyak yang sudah bekerja selama 5-10 tahun yaitu 53 orang (52\%). Responden yang mengalami kelelahan sebanyak 75 orang $(73.5 \%)$ dan yang mengalami stres kerja adalah 76 orang $(74.5 \%)$.

Tabel 2 memperlihatkan hubungan antara kelelahan kerja dengan stres kerja $(\mathrm{p}=0.22)$, shift kerja dengan stres kerja $(\mathrm{p}=0.035)$, jenis kelamin dengan stres kerja $(\mathrm{p}=0.037)$, maupun status pernikahan $(\mathrm{p}=0.041)$ dengan stres kerja. Responden dengan status kelelahan sangat lelah 93.1\% mengalami stress kerja. Stres kerja lebih banyak terjadi pada perawat yang bekerja shift (82\%). Selain itu, hasil penelitian juga menunjukkan bahwa perawat perempuan lebih banyak yang mengalami stres kerja $(80.9 \%)$ dibandingkan dengan perawat laki-laki (61.8\%). Perawat yang belum menikah lebih banyak yang mengalami stres kerja (83.7\%) dibandingkan dengan perawat yang sudah menikah. Sedangkan hasil uji Fisher untuk variabel usia menunjukkan tidak adanya hubungan yang bermakna antara usia perawat dengan stres kerja.

\section{PEMBAHASAN}

Hasil penelitian ini menunjukkan bahwa jumlah perawat yang mengalami stres kerja adalah sebesar $74.5 \%$. Hasil penelitian ini serupa dengan $75 \%$ perawat di rumah sakit yang berafiliasi dengan Universitas Mazardian di Iran mengalami stres sedang sampai berat. ${ }^{(6)}$

Menurut US Occupational Safety and Health Institute, profesi perawat berada di urutan ke-27 di antara 130 profesi lain yang sudah diteliti hubungan antara kerja dan kesehatan mentalnya. Perawat lebih banyak yang bekerja di bawah tekanan dan mengalami stress dibandingkan dengan tenaga medis lainnya. Hal ini dikarenakan pekerjaan perawat memerlukan keterampilan yang tinggi, kewaspadaan yang konstan, kerjasama tim yang kuat dan pelayanan yang bersifat $24 \mathrm{jam} .{ }^{(23)}$

Pada penelitian ini terbukti bahwa shift kerja berhubungan dengan stres kerja pada perawat $(\mathrm{p}=0.035)$. Sebanyak $82 \%$ dari perawat yang bekerja shift mengalami stres kerja. Para perawat yang di RSUD Asy-Syifa Sumbawa Barat yang menjalani shift kerja ini mengalami pola hidup yang tidak teratur dibandingkan dengan yang tidak shift kerja. Hasil penelitian ini sama dengan penelitian yang menunjukkan bahwa shift kerja pagi akan lebih segar karena mengalami proses istirahat yang cukup pada malam sebelumnya dan jumlah perawat yang bertugas pada shift pagi lebih banyak sehingga beban kerja terdistribusi secara merata. (24) Hasil penelitian ini berbeda dengan penelitian yang menunjukkan bahwa tidak ada hubungan shift kerja dengan stres kerja karena perawat yang menjadi responden merupakan perawat di bagian intermediat bedah yang sudah berpengalaman (dengan minimum kerja 2 tahun) dan sudah beradaptasi dengan beban kerja yang tinggi serta adanya hubungan yang harmonis antar perawat dan antara perawat dengan tenaga medis lainnya. Keharmonisan ini mengurangi tingkat stres pada perawat. ${ }^{(17)}$ Hasil penelitian di Vietnam juga menunjukkan bahwa hubungan kerja yang berkualitas tinggi secara signifikans berbanding terbalik dengan stres kerja. Hal ini menyiratkan bahwa dalam hubungan kerja yang positif, para perawat yang didukung dengan sumber daya dan dukungan emosional dari pengawas dan sejawatnya memperlihatkan tingkat stres yang lebih rendah. ${ }^{(25)}$

Hasil penelitian juga menunjukkan adanya hubungan yang bermakna antara kelelahan kerja dan stres kerja $(\mathrm{p}=0.022)$. Perawat yang mengalami stres kerja dan sangat lelah sebesar $93.1 \%$. Hal ini karena masih rendahnya rasio antara jumlah tenaga keperawatan dibandingkan dengan jumlah pasien yang datang sehingga beban kerja menjadi sangat tinggi dan menyebabkan terjadinya kelelahan pada perawat. WHO menetapkan standar rasio ideal perawat dengan pasien adalah 1:200, tetapi data di Indonesia menunjukkan bahwa rasio antara perawat dengan pasien 1: 375. ${ }^{(26)}$

Hasil penelitian ini sesuai dengan penelitian yang memperlihatkan hubungan antara kelelahan kerja dengan stres kerja pada perawat. Hal tersebut sesuai dengan pernyataan bahwa kelelahan kerja berpengaruh terhadap stres kerja seseorang. Semakin tinggi tingkat kelelahan maka semakin besar juga stres yang akan dirasakan oleh seorang pekerja. ${ }^{(20)}$ Hasil penelitian lain menunjukkan bahwa tidak terdapat hubungan antara stres kerja dengan kelelahan kerja pada perawat. Penelitian tersebut dilakukan terhadap Perawat ICU (Intensive Care Unit) pada kategori 
Tabel 2. Hubungan antara shift kerja, kelelahan kerja dan karakteristik demografi dengan stres kerja

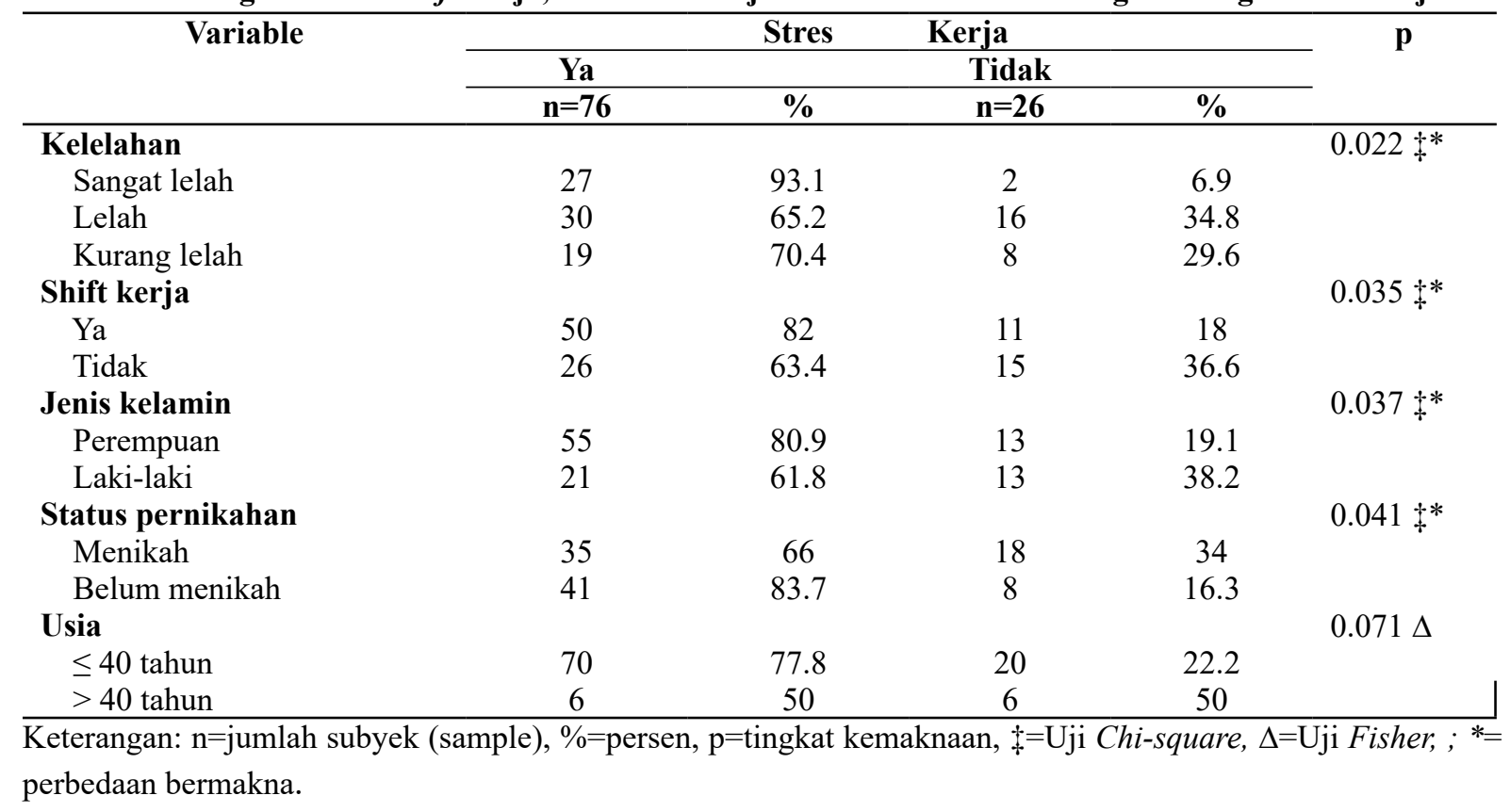

tingkat kelelahan ringan sedangkan pada penelitian ini mayoritas merasakan sangat lelah. Tingkat kelelahan ringan disebabkan oleh kemampuan coping dari responden yang kebanyakan sudah berumur 20-40 tahun (78.8\%) yang biasanya sudah memiliki tingkat kedewasaan, kematangan jiwa dan kemampuan dalam melaksanakan tugas. Pada masa usia produktif sudah terjadi stabilitas dan peningkatan citra diri serta sikap pandang yang lebih realitis sehingga lebih mampu menghadapi masalah dengan perasaan yang lebih tenang. Hal tersebut mengakibatkan tidak ditemukan hubungan antara kelelahan dengan stress kerja. ${ }^{(21)}$

Selain itu juga ditemukan adanya hubungan yang bermakna antara jenis kelamin dan stres kerja pada perawat $(\mathrm{p}=0.037)$. Sebanyak $80.9 \%$ perawat di RSUD Asy-Syifa Sumbawa Barat mengalami stres kerja. Penelitian sebelumnya juga menunjukkan hal yang serupa yaitu persentase perawat perempuan yang mengalami stres kerja berat adalah sebesar 78.6\%. Kecenderungan perempuan mengalami stres kerja lebih besar dibandingkan laki-laki karena perempuan memiliki emosi yang mudah meledak-ledak, selain itu perempuan yang sudah menikah akan menghadapi konflik peran antara perannya sebagai perawat yang bertugas merawat pasien sekaligus sebagai ibu rumah tangga yang harus mengurusi keluarganya. ${ }^{(27)}$ Sedangkan hasil penelitian di Korea menunjukkan hasil yang berbeda di mana perawat laki-laki lebih banyak yang mengalami stres kerja terutama yang berkaitan dengan konflik interpersonal. ${ }^{(28)}$ Pada penelitian di RSUD AsySyifa Sumbawa Barat ini jumlah perawat laki-laki hanya setengah dari jumlah perawat perempuan, oleh sebab itu bila ingin menentukan lebih lanjut hubungan jenis kelamin dengan stres kerja perlu dilakukan penelitian dengan jumlah sampel yang lebih besar.

Hasil penelitian juga menunjukkan adanya hubungan antara status pernikahan dengan stres kerja pada perawat dengan $\mathrm{p}=0.041$. Dalam penelitian ini perawat yang belum menikah lebih banyak mengalami stres kerja yaitu sebesar $83.7 \%$ dibandingkan dengan perawat yang sudah menikah. Status pernikahan merupakan salah satu kebutuhan dari individu, sehingga akan menjadi prediktor baik untuk individu dalam menjalankan aktivitas sehari-hari. Seseorang yang sudah menikah akan cenderung memiliki kepuasan hidup yang baik dan akan mempengaruhi kualitas hidup. Hal tersebut dikarenakan setelah menikah maka akan terjadi pembagian peran dengan pasangan, pekerjaan rumah cenderung akan menurun seiring kerjasama dengan pasangan. Sehingga fokus kepada pekerjaan sebagai professional perawat akan lebih maksimal.(29) Prihatini menyatakan bahwa perawat yang telah menikah mampu mengontrol emosinya dalam menghadapi berbagai macam persoalan baik persoalan internal maupun eksternal, sehingga perawat yang telah menikah lebih tidak mudah stres dibanding 
perawat yang belum menikah. ${ }^{(30)}$ Penelitian ini berbanding terbalik dengan penelitian yang telah dilakukan sebelumnya yang menyatakan bahwa status pernikahan tidak memiliki hubungan yang bermakna dengan stres kerja. Hal ini karena status pernikahan bisa mempengaruhi secara positif maupun negatif pada perilaku seseorang dan juga tergantung bagaimana cara seseorang menilai suatu masalah. ${ }^{(31)}$

Pada penelitian ini memperlihatkan tidak adahubunganantarausiaperawatdenganstreskerja. Hasil penelitian ini sama sejalan dengan penelitian terdahulu yang menunjukkan tidak ada hubungan antara usia dengan stres kerja, karena pada usia ini seseorang sudah cukup banyak pengalaman dan pengetahuan yang telah didapat. ${ }^{(30)}$ Hasil penelitian lain menunjukkan adanya hubungan antara usia dengan stres kerja. Responden pada penelitian tersebut rata-rata berusia 34,2 tahun. Walaupun tidak terbukti berbeda, pada penelitian ini memperlihatkan jumlah perawat yang berusia $<40$ tahun dan mengalami stres kerja lebih tinggi yaitu $77.8 \%$ dibandingkan dengan yang berusia $\geq 40$ tahun $(50 \%)$. Berdasarkan data tersebut, maka dapat dinyatakan bahwa semakin muda usia seseorang maka semakin besar kemungkinan mengalami stres kerja. ${ }^{(13)}$ Hasil penelitian lain memperlihatkan bahwa frekuensi perawat yang berisiko mengalami stres kerja lebih besar pada kelompok usia yang lebih muda yaitu berusia 25 29 tahun. Penelitian tersebut juga menyimpulkan bahwa stress kerja paling rendah pada 35 tahun ke atas. Hasil tersebut berhubungan dengan konsistensi yang lebih besar dan keterampilan yang lebih baik akibat dari pengalaman kerja yang lebih lama. ${ }^{(8)}$

Dalam pelaksanaan penelitian ini terdapat beberapa keterbatasan antara lain tidak melakukan pengukuran terhadap faktor-faktor lain yang dapat mempengaruhi stres kerja antara lain beban kerja, masa kerja, kejenuhan, dan faktor-faktor sosial seperti dukungan keluarga, masalah keluarga dan konflik antar rekan kerja. Faktor-faktor tersebut juga tidak dieksklusi karena adanya keterbatasan dalam keilmuan serta sumber daya.

\section{KESIMPULAN}

Shift kerja, kelelahan kerja, jenis kelamin dan status pernikahan mempunyai hubungan yang bermakna dengan stres kerja pada perawat, tetapi usia tidak didapatkan berhubungan antara usia dengan stres kerja pada perawat RSUD Asy-Syifa Sumbawa Barat.

Diharapkan bagi pihak rumah sakit dapat memberikan perubahan jadwal shift kerja yang lebih bervariatif untuk menghindari risiko terjadinya kelelahan kerja dan stres kerja pada perawat. Selain itu untuk penelitian selanjutnya sebaiknya ditambahkan faktor beban kerja serta faktor-faktor sosial lain yang bisa mempengaruhi stres kerja.

\section{UCAPAN TERIMA KASIH}

Pada penelitian ini penulis mengucapkan terimakasih kepada seluruh direksi dan staf RSUD Asy-Syifa Sumbawa Barat atas izin dan kerjasama dalam penelitian ini.

\section{REFERENSI}

1. Menkes, RI. Peraturan Menkes RI No. 659/ MENKES/PER/VIII/2009 tentang rumah sakit Indonesia kelas dunia.

2. Fajrillah. Nurfitriani. Hubungan Stres Kerja Dengan Kinerja Perawat Pelaksana Dalam Melaksanakan Pelayanan Keperawatan Di Instalasi Gawat Darurat Rumah Sakit Umum Anutapura Palu. Jurnal Keperawatan 2016;3(2):16-24.

3. Mwachofi A, Walston SL, Al-Omar BA. Factors affecting nurses' perceptions of patient safety. Int J Health Care Qual Assur. 2011;24(4):274-83.

4. Rustiani ER, Cahyati WH. Stres Kerja Dengan Pemilihan Strategi Coping. KEMAS 2012;7(2):149-155.

5. Marchelia V. Stres Kerja Ditinjau Dari Shift Kerja Pada Karyawan. Jurnal Ilmiah Psikologi Terapan 2014;2(1):130-43

6. Asefzadeh S, Kalhor R, Tir M. Patient Safety Culture and Job Stress Among Nurses In Mazandaran, Iran. Electron Physician. 2017;9(12):6010-6016. doi: $10.19082 / 6010$.

7. Desima R. Tingkat Stres Kerja Perawat Dengan Perilaku Caring Perawat. Jurnal keperawatan 2013;4(1):43-55.

8. Najimi A, Gourdazi AM, Sarifirad G. Causes of Job Stress in Nurses: A Cross-Sectional Study. Iran J Nurs Midwifery Res. 2012;17(4):301-305.

9. Saravis P, Rousaki E, Tsounis A, et.al. The Impact of Occupational Stress on Nurses' Caring Behaviours and Their Health Related Quality of Life. BMC Nurs. 2016;15:56. doi: $\underline{10.1186 /}$ s12912-016-0178-y

10. Sorra JS, Dyer N. Multilevel psychometric properties of the AHRQ hospital survey on patient safety culture. BMC Health Serv Res. 2010;10:199.

11. Seragih H. Rochadi K. Lubis, HA. Pengaruh Karakteristik Organisasional Dan Individual Terhadap Stres Kerja Di Ruang Rawat Inap RSUD Porsea.Tesis.Sekolah Pascasarjana Universitas Sumatra Utara Medan. 2008

12. Febriana SK. Faktor-Faktor Yang Mempengaruhi Stres Kerja. Jurnal Ecopsy 2013 Des;1(1):28-32.

13. Fitri AM. Analisis Faktor-Faktor Yang 
Berhubungan Dengan Kejadian Stres Kerja Pada Karyawan Bank. Jurnal Kesehatan Masyarakat 2013;2(1)

14. Mareta DC. Safitri W. Nurhidayati A. Hubungan Karakteristik Perawat Dengan Stres Kerja Di Ruang Perawatan RSUD dr. Soehadi Prijonegoro Sregen. Skripsi. STIKES Kusuma Husada Surakarta. 2016.

15. Joko S. Titin IO. Sigit TS. Pengaruh Shift Kerja Terhadap Kelelahan Karyawan Dengan Metode Bourdon Wiersman Dan 30 Items Of Rating Scale. Jurnal Teknologi.5(1):32-9.

16. Putri RK. Gambaran Stres Kerja Pada Perawat Shift Malam Di Ruang IGD RSUD DR. Pirngadi Medan. Sumatra Utara. Skripsi. USU;2009.

17. Nursalam, Sunarno A, Fitriyah R. Hubungan Shift Kerja Dengan Stres Kerja Dan Circadia Rhythm Perawat. Journal OfOccupational Health.81:32-52.

18. Dian K. Sholikhah. Hubungan Kelelahan Kerja Dengan Kinerja Perawat Di Bangsal Rawat Inap Rumah Sakit Islam Fatimah Kabupaten Cilacap. Jurnal Kesehatan Masyarakat.6(2):162-232.

19. Hariyono W, Suryani D, Wulandari Y. Hubungan Antara Beban Kerja, Stres Kerja Dan tingkat Konflik Dengan Kelelahan Kerja Perawat Di Rumah Sakit Islam Yogyakarta PDHI Kota Yogyakarta. Jurnal Kesehatan Masyarakat. 2009;3(3):186-97.

20. Undap S, Ratag BT, Kawatu PA. Hubungan Antara Kelelahan Kerja Dengan Stres Kerja Pada Perawat UGD Dan ICU RSUD Kota Bitung. Fakultas Kesehatan Masyarakat Universitas Sam Ratulangi. Jurnal IKMAS. 2016;1(3).

21. Kurnia HK, Intan N. Hotmaida L. Hubungan Tingkat Stres Kerja Dengan Tingkat Kelelahan Kerja Perawat ICU RS Immanuel Bandung. Jurnal Ilmu Kesehatan 2015;9(1):487-500.

22. Putri YW. Pengaruh Shift Kerja terhadap Kelelahan Kerja Pada Karyawan Instalasi Rawat Inap I RSUP Dr. Sardjito Yogyakarta. Skripsi. Fakultas Kedokteran Universitas Sebelas Maret. Surakarta. 2011.

23. Akbar RE, Elahi N, Mohammadi E, Khoshknab MF. How Do the Nurses Cope with Job Stress? A Study with Grounded Theory Approach. J Caring Sci. 2017;6(3): 199-211. doi: $10.15171 /$ jes.2017.020.

24. Konoralma, K. Moningka, L. Palamani, S. Hubungan Shift Kerja Perawat Dengan Stres Kerja Di Ruang IRDM BLU RSUP Prof. DR.R.D. Kandou Manado. Poltekkes Kemenkes Manado. Jurnal Ilmiah Perawat Manado. 2013.16-24.

25. Tran KT, Nguyen PV, Dang TTU, Tran NBT. The Impacts of the High-Quality Workplace Relationships on Job Performance: A Perspective on Staff Nurses in Vietnam. Behav Sci (Basel). 2018; 8(12):109. doi: 10.3390/bs8120109.

26. Indrianti R, Hadi C. Hubungan Antara Modal Psikologis Dengan Keterikatan Kerja Pada Perawat di Instalasi Rawat Inap Rumah Sakit Jiwa Menur Surabaya. Jurnal Psikologi Industri dan Organisasi. 2012.Vol.1 No. 03:120-125.

27. Russeng SS, Usman M, Saleh LM. Stres Kerja Pada Perawat Di Instalasi Rawat Inap Rumah Sakit DR. Tadjuddin Chalid Makassar. Media Kesehatan Masyarakat Indonesia. FKM Unhas. 2007;3(1):156.

28. Joohyun L, Hee YC. Gender Differences in Job Stress and Stress Coping Strategies among Korean Nurses. International Journal of Bio-Science and
Bio-Technology Vol.8, No.3 (2016), pp. 143-148. http://dx.doi.org/10.14257/ijbsbt.

29. Hardani. Stres Kerja Dan Kepuasan Kerja Dengan Kualitas Hidup Perawat ICU Di RS Tipe B. Journal Endurance 2016 Oct;1(3):113-120.

30. Prihatini. Analisis Hubungan Beban Kerja Dengan Stres Kerja Perawat Di Tiap Ruang Rawat Inap RSUD Sidikalang. Tesis. Medan. USU. 2007.

31. Ismafiaty. Hubungan Antara Strategi Koping Dan Karakteristik Perawat Dengan Stres Kerja Di Ruang Perawatan Intensif RS Dustira Cimahi. Jurnal Kesehatan Kartika.2011.hlm. 37-52. 